\title{
DISCURSIVE CITIZENSHIP: THE BODY POLITIC IN CYBERSPACE ${ }^{1}$
}

\author{
Beth Kolko \\ University of Washington \\ Seattle, Washington, USA
}

\begin{abstract}
Questions of community and identity dominate discussions of cyberspace. Recent work in a variety of disciplines points to a fluidity of identity within virtual environments that is both a determining factor in how the space is used and also a way to begin theorizing the possibilities of the space. Mark Poster, Sherry Turkle, Alluecquere Stone, Lisa Nakamura, and Jennifer Mnookin are a few of the scholars who have provided wide-ranging analyses that resonate with one another in their portrayals of dispersed and fragmented presences in virtual communities. These questions of identity have variously raised issues relating to the body, and much current research on cyberspace addresses the ways in which the material is implicated in the virtual.

This paper explores how discursive formations of identity affect community development in virtual environments, primarily with regard to experiments in governance within online communities. In particular, the paper examines how the collaborative nature of cyberspace complicates effective use of virtual environments for complex community functions. While focusing on rhetorical theory, the paper argues that traditional relations between speaker and audience are blurred substantially in cyberspace, sufficiently so that attempts at establishing a kind of communicative ethics online are difficult at best. The premise that cyberspace communities, in particular MUDs (multiuser domains) and MOOs (multiuser object oriented environments), are writing environments wherein discursive negotiation plays a major role in community formation frames the analysis of the rhetorical function of place. Although new media, and increased bandwidth, are expanding the kinds of sign systems that are used to communicate in cyberspace, the claim to identity online is still very much a matter of discursive choice.
\end{abstract}

\section{Writing Matters}

Some time ago, I spent several years researching writers of a particular genre fiction. What I found during the course of that project is that a community of writers, whether their work centers around a shared text or on the writing process more generally, can learn to collaboratively negotiate the culture that circumscribes them. Group members learn to use the act of writing as a way to intercede in and mediate an array of cultural forces, and the many ways in which both rhetorical theory and post-structuralism regard writing as an act of self-creation are instantiated by the work members do individually and as a group to self-define as writers, as agents, as creators of culture.

Jim Berlin, a rhetoric and writing theorist, traces developments in rhetorical theory over the past century, and he focuses on a shift to what he calls epistemic rhetoric, a form of social constructionism that dovetails with postmodern theories of the self. In an analysis of writing practices within educational institutions Berlin chronicles, "the emergence of a social epistemic rhetoric, a rhetoric that considers

1 Portions of this article appeared previously in Dissolution and Fragmentation: Problems in Online Communities with Elizabeth Reid Steere in Cybersociety 2.0, Ed. Steven Jones, Sage Press, Thousand Oaks. 1998. pp. 212-229. At the author's request, the IJVR acknowledge that like many of the articles in this issue, the original submission was several years ago. In this case 1998. 
signifying practices in relation to the ideological formation of the self within a context of economics, politics, and power" (109). Berlin goes on to claim that "[s]ince language is at the center of the formation of the subject, serving as the mediator between material conditions and the individual, writing--text production--is a manifestation of the central process of self and social formation" (113). His argument here captures the sense of import in a writing group's activity, and it speaks directly to what the research on the genre writers found meaningful. ${ }^{2}$

Perhaps it was because I was in the midst of that previous research when I stumbled upon virtual communities, but my initial perspective on MOOs was that participants in cyberspace form a kind of writing community similar to that of the genre writers. ${ }^{3}$ Although it remains to be persuasively and finally argued to what extent writing within virtual communities represents primary/secondary orality/literacy, the discursive nature of existence in text-based environments is incontestable as a component of virtual interaction. Within online communities, in fact, a particularly powerful kind of writing occurs; when we write in cyberspace, we create -- in quite literal terms, we create a world with our words. But the intercession, the interruption of defining forces, the reinscription of identity that the genre writers performed through their participation in writing groups is precisely the same kind of activity we can see among those who re-define themselves within online space, who seek to redraw boundaries of gender or ethnicity, who proclaim an alternate nationstate alliance or religious affiliation. The play of and with identity online is a discursive resistance, the very kind that writing theorist Linda Brodkey portrays as an interruptive practice that seeks to reform the larger culture and one's role within it, a use of words that brings the body, the material, to the forefront. She characterizes discursive resistance as practices wherein:

individuals who are ambivalent or threatened by their subject positions in a given discourse...interrupt the very notion of the unified self--the traditional Cartesian notion that the self is a transcendent and absolute entity rather than a creation of language and ideology-in their spoken and written texts. Such interruptions are likely to take one of two forms: reversing the negative and positive subject positions in a given discourse--as Carol Gilligan does in her feminist revision of the research on the development of moral reasoning among adolescent girls; or re-presenting a stereotype as an agent in a discourse the least committed to the preservation of the stereotype--as Toni Morrison does in representing AfricanAmerican women and men as the agents rather than the victims of events in her novels.

I would add to her categories of discursive resistance the acts of self-creation within virtual communities, whether by studied and detailed alterations of how one self-presents (such as changing gender or race) or by some of the more subtle characterizations Turkle relates in her study of people who make use of MUDs in order to give expression to normally suppressed components of their personality.

The virtual self may be disembodied and multiple, but it is still embodied at some point: the place where access matters, and bandwidth is a crucial variable; the place where RSI occurs; the place where laws regarding free speech and harassment collide not just with one another, but also with the words that participants in the virtual community contribute. For while the world may very well be virtual, the words are not. And thus the discursive resistance that comprises online interaction has material, and political, consequences.

2 See also Jenkins.

3 I use the term "writing" community as a shorthand here. A variety of work has been done exploring the idea of secondary orality and/or literacy with respect to writing online, and these arguments are compelling. However, they do not obviate the central force discourse holds within text-based virtual communities. 
That discursive resistance is facilitated by virtual communities is not to say the process is uniform or total. Analyses of access and fluency required to participate are only some of the questions that qualify this conversation. At the same time, however, it is useful to consider the discursive structures of cyberspace in order to gain a more complete understanding of how virtual communities work, and, perhaps, also an understanding of why they often do not work.

\section{Virtual Interruptions}

The fluidity of identity within cyberspace affects virtual interactions in substantial ways. For all the liberatory potential of such self-reinscription, the tales of relationships formed under these circumstances can also contain less celebratory themes. The research on virtual communities is filled with tales of masks of age and race, gender and class, masks of almost every aspect of identity. These are tales that do not always have happy endings. The stories of online cross-dressing that abound, for example, often culminate in narratives of betrayal. In this accumulated body of scholarship, participants talk of how their notions of the world and their selves and others has been destabilized, rocked beyond recognition, until they are left feeling adrift, asea, that they 'cannot trust anyone,' that 'everything online can be a lie,' that 'no one tells who they really are.' Limited bandwidth necessitates that when we venture online, we lose our ability to transfer the social codes and cues of face to face interaction to online environments. These kinds of warnings are now part of the folklore of cyberspace; even usage agreements from many providers now alert new members that they cannot always trust virtual appearances. But the point is that the interruptive practices of discursive resistance associated with the fluidity of the self yield both constructive and destructive narratives. ${ }^{4}$ What seems less examined, though, is the way interruptive practices are associated with the fluidity of space in virtual environments.

The architecture of cyber spaces pushes against formal boundaries just as much as the construction of cyber selves. Geopolitical affiliation is masked in much the same way that gender, or age, or race are. This is not to say that any of these characteristics can be wholly effaced, but there are ways to conceal them, and, the more one tries, the more such traces can be mediated. However, the absence of impermeable walls within a virtual community (what with the ability to page and shout), and the way they resist traditional space and time constrictions on human communication (what with the ability to whisper and remote emote), have just as destabilizing effects on exchanges within cyberspace as the fluidity of identity.

Place has always been tied to rhetorical authority; deconstructing space reconstructs our understanding of rhetoric. The structures of cyberspace consequently affect online lives from the standpoint of communicative ethics. The overlap of work and play in spaces has economic ramifications, and the reformation of domestic space effected by communication technologies has significant consequences from the perspective of feminist theory. But the arrangement of space within virtual communities wreaks havoc on a traditional understanding of communication, particularly with respect to conceptions of private and public space. Rhetoric is about relationships, the shifting connections among ethos, logos, and pathos. It is the relationship among these points that changes, but the points themselves are identifiable in relation to the others. It is the disruption of this very relation that is so disturbing in attempts to communicate with some -- authenticity-- in cyberspace. The fluidity of space combines with the fluidity of identity in cyberspace, further imperiling the ability to talk with any sense of familiarity, with any commitment to codes of the world we know and move through daily in real space. It is in the experiments in online governance that we can most clearly see the stakes of trying to carve public space out of the amorphous landscape of cyberspace.

\footnotetext{
${ }^{4}$ See also Turkle, McRae, Stone, Doheny-Farina.
} 


\section{Silences in/of Cyberspace}

In a critique of urban structures, M. Christine Boyer writes of non-virtual realms, "in the bodily disenchantment that haunts our postmodern era, if the self is unstable, dephysicalized, and thus beginning to disappear, making projections from it ambiguous and unclear, then the image of the city as a normally functioning or healthy body also begins to be undermined. Thus the corporeal analogies of body/architecture and body/city under posthumanist, poststructuralist thought are marked by zones of silence, estrangement, and emptiness" (80). Boyer's critique of city structures in light of how they accommodate a disappeared body relates significantly to cyberspace and the virtual structures that (fail to) define its boundaries. That is, as virtual communities similarly tend to displace (but not efface) the material, the categories of space and interaction with which we are most familiar dissolve. The "zones of silence" she names here are markedly evident in cyberspace, a telling estrangement of people from their words, from others, from their communities.

Although I am dedicated to the idea that online communities have tangible and positive effects on peoples lives in real space, that the boundaries between the two, indeed, blur substantially, I am forced to make a concurrent argument that virtual communities seem to be less effective along other lines. This histories written of LambdaMOO, for example, catalogue a variety of communicative failures, incidents where breakdown in the ability of the community to collaborate effectively interrupted daily routines. ${ }^{5}$ When William Mitchell raises the question of the civic character of cyberspace communities, when he says, "[w]e will have to figure out how to make cyberspace communities work in just, equitable, and satisfying ways" (160), he introduces an imperative that has yet to be met. If we do want to envision virtual communities as able to serve as public, and perhaps transformable, space, as a viable cultural force, then we must come to a more complete understanding of how language, as a building block of what occurs there, works within virtual environments.

\section{Collaboration and Community}

Slightly over four years ago, a graduate student started a virtual community for media researchers, a membership-only MOO. As of January 9, 1997, almost four years into its existence, this MOO had 919 members, 37 countries represented among the membership, and an average daily login maximum of 13 users. Membership is by a formal and yet not very strict application process. Many participants are academics; the group also includes programmers, students, artists, and a variety of that "other" category. Roughly three years ago, this community embarked on an experiment in virtual governance; until that point it had been operating as many such virtual environments do--under the benign dictatorship of its arch-wizard. The roots of the decision to change the structure of the community were well-tangled, and the different parties involved--the wizards, the handful of members who first raised the issue of alternative modes of governing the community, the larger group that participated in an initial "town meeting" to discuss the idea, and the greater number of those who remained uninterested and uninvolved with the discussions--each came to the experiment with vastly different ideas and expectations.

It is possible to claim that this experiment was doomed from the outset because of the particulars of how the decision was made to create what came to be known as the council. And, in fact, I suspect that particular analysis would be an important one to conduct at some point. It is not, however, the story I am going to tell here. Rather, I want to focus on the dissolution of the council, and the series of events that led its members to their final stages of frustration. In ethnographic terms, this story comes down a bit

\footnotetext{
${ }^{5}$ See Dibbell, Mnookin, Stivale.
} 
heavily on the participant side of the participant-observer relationship; I was a member of that council and this paper grows out of nearly three years of trying to make sense of what happened during those months. One might also claim that, given what we know of ethnographic methodology, what follows is a story, one version only of the many possible narratives that could be told of these events.

The particulars of the case that led to the end are less germane; it was a case of harassment, complicated by evidence and testimony that spanned several different virtual communities and by the differing nationalities of the plaintiffs, accused, and council members. We cast about for some legal guidelines, but could rely on neither institutional nor national boundaries to provide a framework. Additionally, two of the six council members were involved in the case, and so they recused themselves, leaving four of us left to adjudicate. We had no precedents, no legal backdrop, and not even much of an indigenous social code to guide the decisions. We did, as we claimed, the best we could. We talked to people, read logs that were submitted, re-interviewed participants. We established a mailing list for the four of us to facilitate conversations, weigh evidence, and tentatively spin out some decisions and rationalizations for those decisions.

The process was frustrating to those at the center and on the margins. But what grew most disconcerting was not the actual process of coming to some sort of judgment. I believed the process itself was an effective use of time. The case was fascinating, challenging, and demanded a great deal of creative thinking and charting of new ground; by and large I felt we were engaged in something important, something worthwhile. It was the after-effects of the decision, however, that were so excruciating.

The council reached a decision that met with some objection from a handful of community members. (This is a curious story to relate since the participants are in many cases colleagues, but I'm not interested in dwelling on the particular fault lines of disagreement.) However, it is the fact that such fault lines persisted, despite best efforts at discursive negotiation that was so marked.

Earlier, this paper made the case for MUDs and MOOs as writing environments, a place where discourse is all-powerful, where linguistic negotiation is the only real weapon. In the aftermath of the council's decision, different versions of how the council proceeded circulated. One example: the fact that two council members were part of the plaintiff collective. One of the first decisions the council made was to have those two members recuse themselves. And we subsequently disregarded their testimony, aware of the conflict of interest potential, and the ways in which personal relationships could affect the outcome. Whether or not the council protected itself sufficiently from claims of bias is not the case here. What is crucial is that the council's attempts at self-representation in terms of the decision-making process were relegated to the "zone of silence" Boyer names. Stupefying amounts of text were posted to internal mailing lists; accusations were relentless. Despite the numerous posts put forward by council members regarding the process followed, no middle ground was ever identified. Resentment on all sides grew, and the resulting acrimony made it difficult to reclaim any sense of community spirit, any sense of shared objectives.

In the wake of the furor over the council's decision, we were forced to ask what led to this particular failure. I could provide a variety of possible explanations. It might be that the council just did a bad job. Or it might be the result of the MOOs' members being drawn from a variety of countries and having a diversity of experience and expectations with governance systems. It could have been tied to the 
MOO being populated by people with wildly diverging ideas on what the goal of the MOO should be. The failure could also be related to an ultimately flawed sense of public versus private within the community, a blurring of virtual space that made it impossible for clear function to follow unclear form. ${ }^{6}$

From the perspective of a rhetorician, the lesson in this ultimate breakdown seemed a quite clear lesson that virtual communities are not the agora, that they are not a place of open and free public discourse. And while I am loathe to accept this one failed experiment as evidence that MOOs cannot be a space of constructive public discourse, the narratives of LambdaMOO substantiate similar claims.

Julian Dibbell's piece is perhaps the best-known version of community breakdown at Lambda. Jennifer Mnookin and Charles Stivale have related similar kinds of stories about Lambda; each of these pieces chronicles in detail the ways attempts at governance online have ultimately failed to adjudicate disagreements without incurring rancor within the communities. These failures of a kind of community collaboration in a virtual public sphere are clear impediments to making cyberspace communities work, as Mitchell calls for, "in just, equitable, and satisfying ways."

Among the variety of explanations for these failures is the claim that such breakdowns within virtual communities may be tied to space, and the role of place with respect to rhetoric. What seems clear is that the authority to speak is tied to place in quite substantial ways. The decoding of ethos, for example, requires a situated speaker. Given the fluidity of space in a virtual community, we lose those markers of place that confer rhetorical authority. It seems necessary, somehow, to find ways to contend with the messiness of virtual space, with the conflation of different purposes for the space, with the myriad roles a virtual community takes on for individuals. Without recouping in some sense the idea of place and rhetorical authority within the virtual environment, we will be limited in our progressive uses of such media.

Cyberspace is a consensual hallucination, but for us to achieve those just, equitable spaces, do we not also need cyberspace to be a place of consensual discourse? It is, in fact, the breakdown of such consensus that leads to the stories we see about LambdaMOO; it is the refusal to engage in consensual discourse that led to the tenor of the debates over governance on the professional MOO I discussed earlier. We do not have consensual discourse in cyberspace. I would argue that, more often than not, we do not have consensual discourse as a thematic of cyberspace. The multiplicity of roles and spaces, the competing notions of what use we are to make of virtual communities, inevitably leads to a failure of rhetorical analyses as we have grown dependent on them in the face to face world. (When does a hallucination become a nightmare?) Concurrently, there is something disquieting about unrelenting consensus; it tends to silence difference. Again, in order to achieve those just and equitable spaces must cyberspace become an agonistic hallucination? Rather than consensual discourse, can we build communities based on sophistic discourse?

6 Curiously enough, attention was paid, however haphazardly, to the relationship of virtual spaces to the function of the MOO. We had virtual architectural spaces to facilitate the attempt at governance; we had a council meeting room which, when it was accused of Star Chamber overtones, was modified to log the meetings, and, eventually, to allow one-way viewing of the council meetings by committee members. The meetings were not open to everyone for the particular reason the model of representative democracy was chosen. Through the very generous donation of programming time from one member, the MOO was equipped with a variety of structures that facilitated communication. 
The body politic in cyberspace is as fragmented as the self in cyberspace. The fluidity of national boundaries overlaps with the permeability of virtual structures, giving rise to amorphous spaces that leave physical situatedness an ineffective category. It seems that with the loss of the traditional nexus of place and power, we are left with the necessity of crafting an alternate way of viewing rhetorical relationships. Discursive resistance needs a place to act upon, whether that place is a body or a space. The mediation of one and the blurring of the other within virtual communities stands as an unmet challenge in crafting such cyberspaces into viable public forums.

\section{REFERENCES}

Berlin, James. "Composition Studies and Cultural Studies: Collapsing Boundaries." Into the Field: Sites of Composition Studies. Ed. Anne Ruggles Gere. New York: MLA, 1993. 99-116.

Boyer, M. Christine. Cybercities: Visual Perception in the Age of Electronic Communication. Princeton: Princeton Architectural Press, 1996.

Brodkey, Linda. "On the Subjects of Class and Gender in 'The Literacy Letters," in Writing Permitted in Designated Areas Only. Minneapolis, ～U Minnesota P, 1996.

Dibbell, Julian. "A Rape in Cyberspace." The Village Voice . (December 21, 1993): 36-42.

Doheny-Farina, Stephen. The Wired Neighborhood. New Haven: Yale UP, 1966.

Jenkins, Henry. Textual Poachers: Television Fans and Participatory Culture. New York, Routledge, 1992.

McRae, Shannon. "Coming Apart at the Seams: Sex, Text, and the Virtual Body." Wired_Women: Gender and New Realities in Cyberspace. Ed. Lynn Cherny and Elizabeth Reba Wiese. Seattle, Seal P, 1006. 242-264.

Mitchell, William. City of Bits: Space, Place and the Infobahn. Cambridge, MIT Press, 1995.

Mnookin, Jennifer. "Virtual(ly) Law: The Emergence of Law in LambdaMOO" Journal of ComputerMediated Communication . 2:1: Part 1 of a Special Issue, June, 1996.

Poster, Mark. The Second Media Age. Oxford:Polity-Blackwell, 1995.

Stivale, Charles J. "'help manners': Cyber-Democracy and its Vicissitudes", Originally presented 29 December 1995, further revision on 20-21 May 1996.

http://wwwpub.utdallas.edu/ cynthiah/lingua archive/help manners.html

Stone, Allucquere Rose. The War of Desire and Technology at the Close of the Mechanical Age. Cambridge, MIT Press, 1995.

Turkle, Sherry. Life on the Screen: Identity in the Age of the Internet. New York: Simon \& Schuster, 1995. 


\section{BIOGRAPHY}

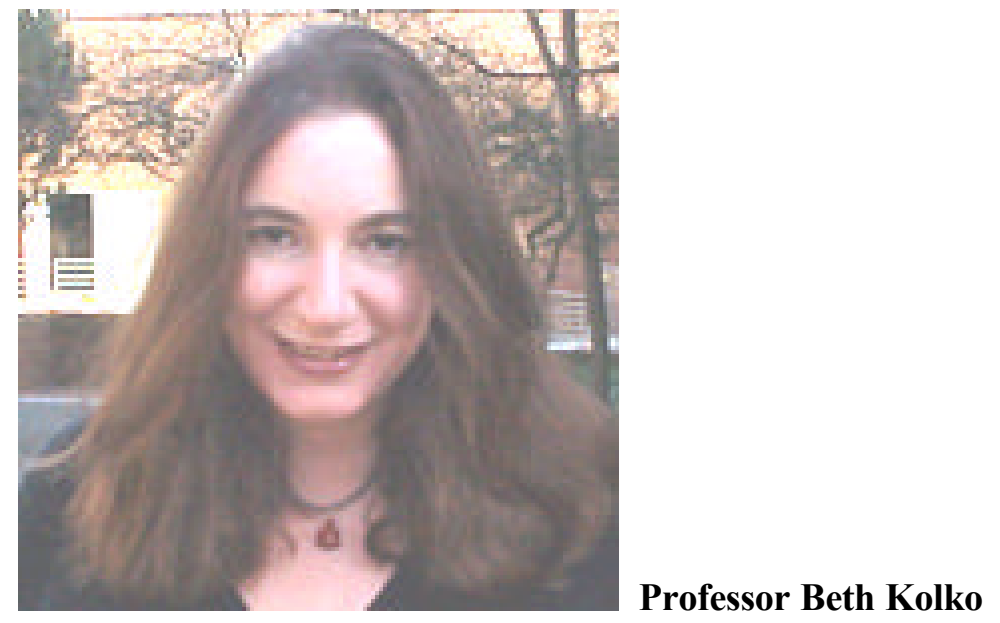

Beth Kolko is an Associate Professor in the Department of Technical Communication at the University of Washington. She was previously a professor of English at the University of Wyoming and the University of Texas at Arlington.

Her work in the early 1990s focused on rhetorical theory and cultural studies with an emphasis on writing as a social act. Studying writers in informal educational settings, both offline and online, sparked her interest in the Internet (which was then text-based) as a writing environment which provided users the ability to put into practice post-structural modes of engagement. Her work on virtual communities at that point began to include visual representations of users in online environments and issues related to community fragmentation online. That work was tied to her long-term interests in how identity and diversity impact people's use of technology. Her chapter "Erasing @race: Going White in the (Inter)Face" in her co-edited volume Race and Cyberspace framed the argument about diversity and technology in terms of interface design and assumptions about users. Other work in the area has included establishing a virtual world, MOOscape, which was the first of its kind to incorporate race as an element of online identity.

Her current research further develops the idea of diversity and technology by focusing on Internet development in Central Asia. The goal of this project is to apply theory-based analyses of culture and technology in order to concretely affect how technology is being used in diverse communities. In 2000, she was a Fulbright Scholar in Uzbekistan where she researched early information and communication (ICT) development in the region. In 2002 she received a grant from the National Science Foundation to expand this work with subsequent qualitative and quantitative analyses. In November 2002 she conducted field research in Tashkent and Bukhara, and in February 2003 she will return to the region to distribute surveys and conduct further field observations.

\section{Contact information:}

14 Loew Hall

Box 352195

Seattle, WA 98195

Phone: 543-2567 Fax: (206) 543-8858

Email link: mailto:tc@uwtc.washington.edu 